\title{
Myoclonus epilepsy with cerebellar Lafora bodies Report of a case
}

\author{
R. SCELSI, G. L. MAZZELLA, AND M. LOMBARDI \\ From the Instituto di Anatomia Patologica e Clinica delle Malattie Nervose e Mentali \\ della Università di Pavia, Pavia, Italy
}

SYNOPSIS A case is reported of an 18 year old man with progressive myoclonus epilepsy. Histopathological examination revealed the presence of numerous Lafora bodies in the cerebellar granular layer, without other significant changes in the central nervous system or in other organs.

Histological alterations of the cerebellum in some cases of progressive myoclonus epilepsy have been described previously (Ammermann, 1940; Anraku et al., 1965; Matthews et al., 1969; Koskiniemi et al., 1974; Van Heycop Ten Ham, 1974). Lafora bodies were not constantly present, but they were associated with other alterations such as cellular depletion of the granular layer, loss of Purkinje cells, and degenerative changes in the dentate nucleus.

The following is a familial case of progressive

(Accepted 11 November 1975.) myoclonus epilepsy with typical clinical findings and with the presence of Lafora bodies in the granular layer without other microscopical abnormalities in either cerebellum or other organs.

\section{CASE REPORT}

M.G., an 18 year old male, was the lastborn of four brothers and one sister. The first and second born males died at the ages of 18 and 24 years from 'status epilepticus'. When 15 years old the patient had his first fit and successive myoclonic twitches of

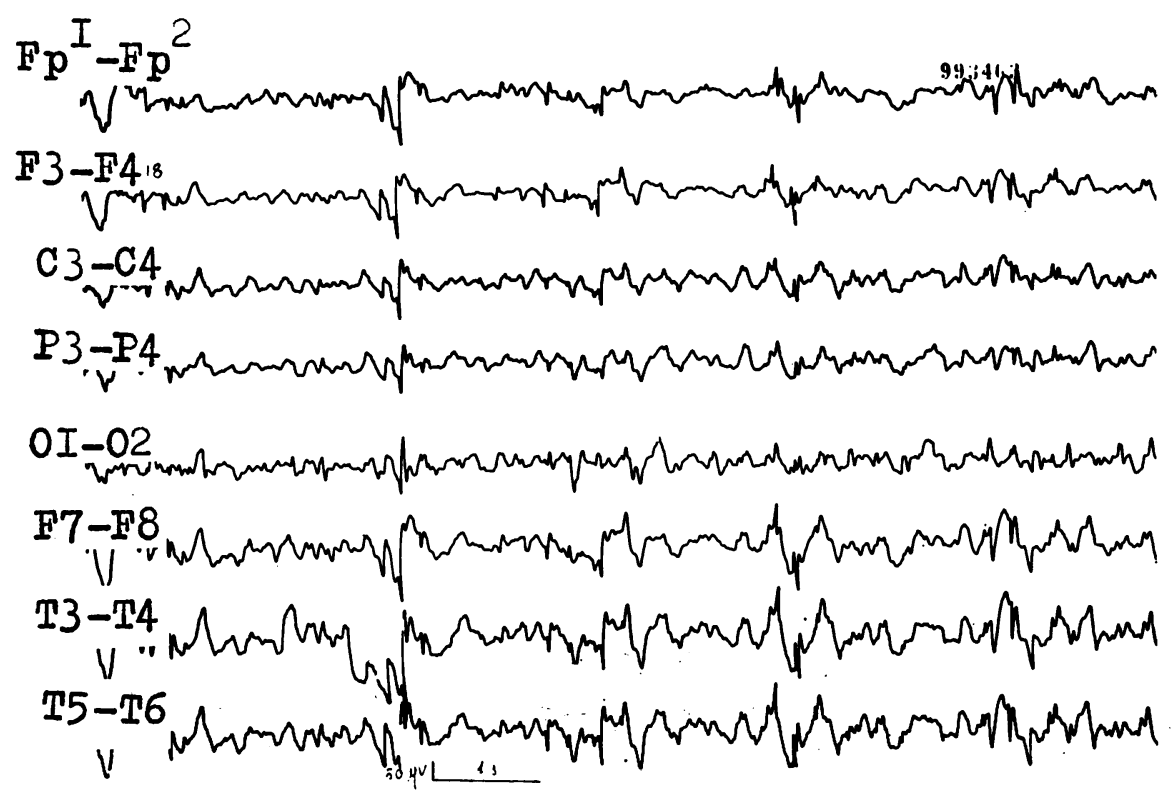

FIG. 1 EEG recorded two months before death. Calibrations $50 \mu V$ and $1 \mathrm{~s}$. 


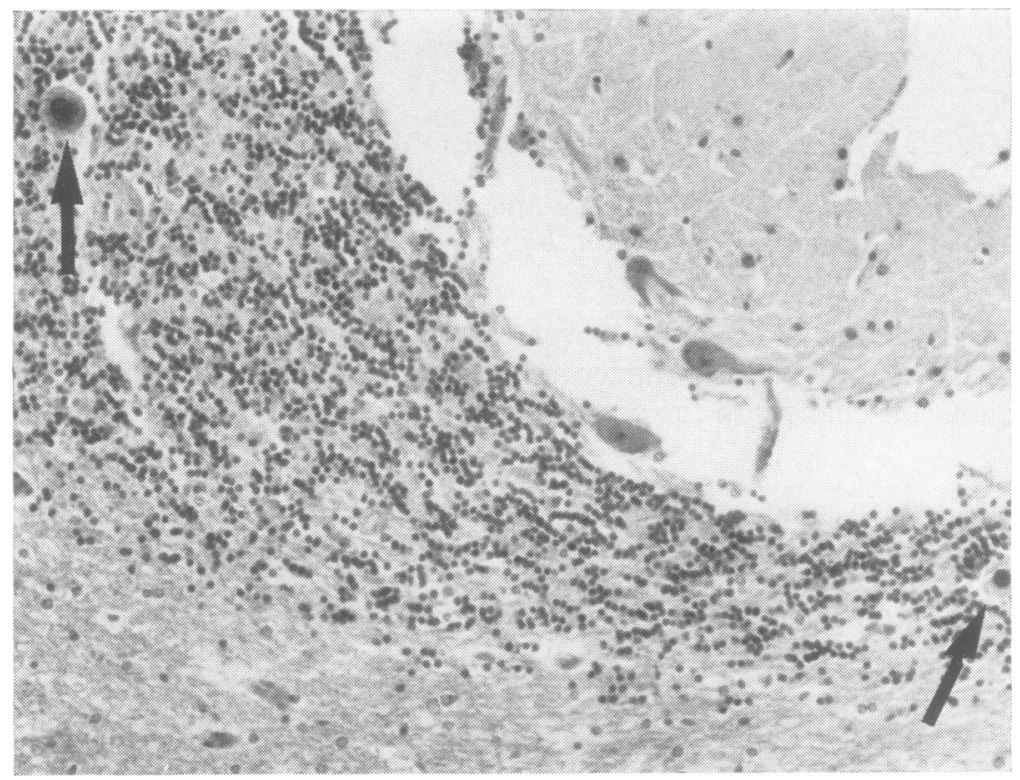

FIG. 2 Distribution of Lafora bodies (arrows) in the granular layer of the cerebellum.

Haematoxylin and eosin ( $H$ and E), $\times 100$.

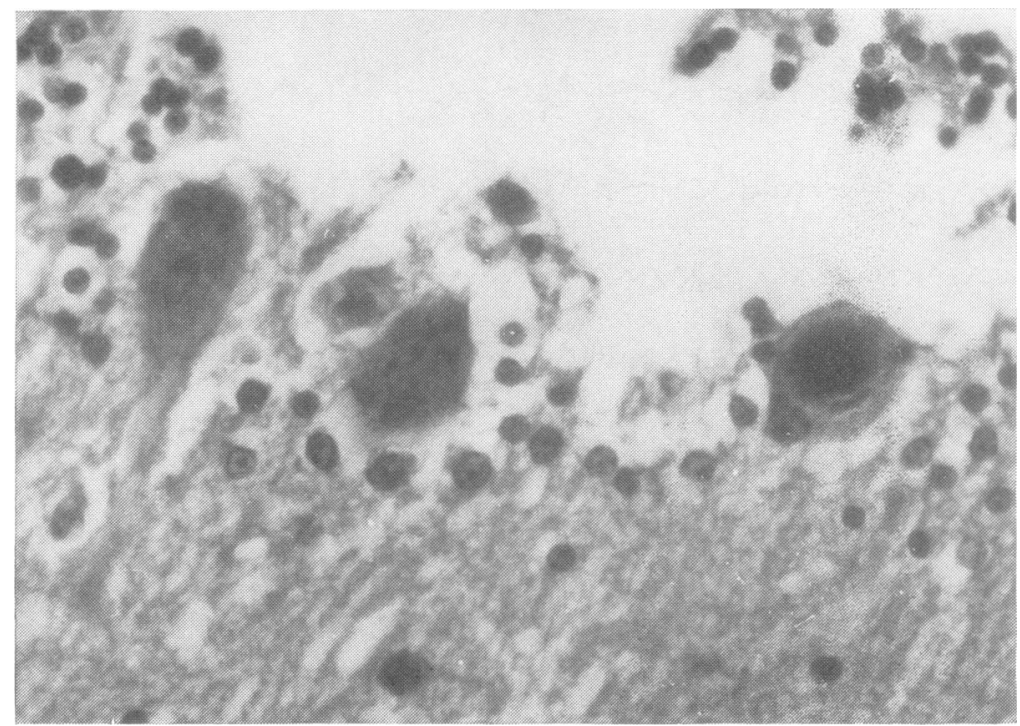

FIG. 3 Lafora body in the Purkinje cell layer of the cerebellum. $H$ and $E, \times 1000$. 


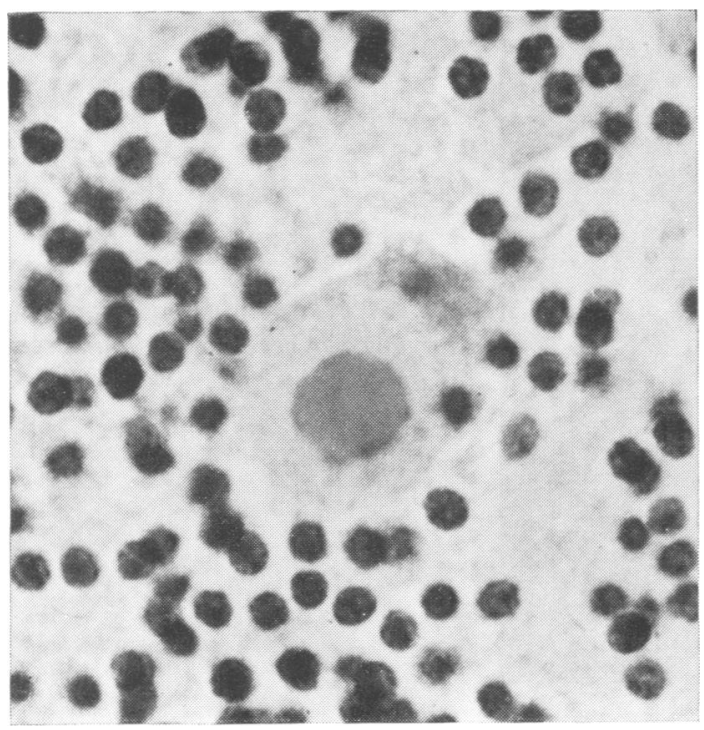

FIG. $4 A$ Lafora body in the granular layer of the cerebellum. $H$ and $E, \times 1000$.

the face and limbs, with progressive mental deterioration.

The patient came under our observation when at 18 years of age he had one or two fits once or twice a week and myoclonus of the facial muscles and limbs. These symptoms were accompanied by cerebellar signs such as nystagmus, scanning speech, dysmetria, dysdiadokinesia, ataxia, and severe dementia. After 11 months the patient died from bronchopneumonia. Laboratory investigations did not demonstrate any abnormalities. Pneumoencephalography showed cortical cerebral atrophy. Cerebral scintigraphy was normal. The EEG record was dominated by theta and delta synchronous activity; at brief intervals there was superimposition of many spikes and sometimes spike-wave complexes bilaterally (Fig. 1). Photic stimulation moderately accentuated spikes within the middle frequencies. Hyperventilation could not be performed. The tracing remained virtually unchanged during successive investigations.

A deltoid muscle biopsy performed five months before death showed patterns of type 2 muscle fibre atrophy: enzyme-histochemical reactions demonstrated the presence and homogeneous distribution of the fibre types. In particular, no PAS positive or basophilic deposits were found in the muscle fibres or in the interstitial tissues.

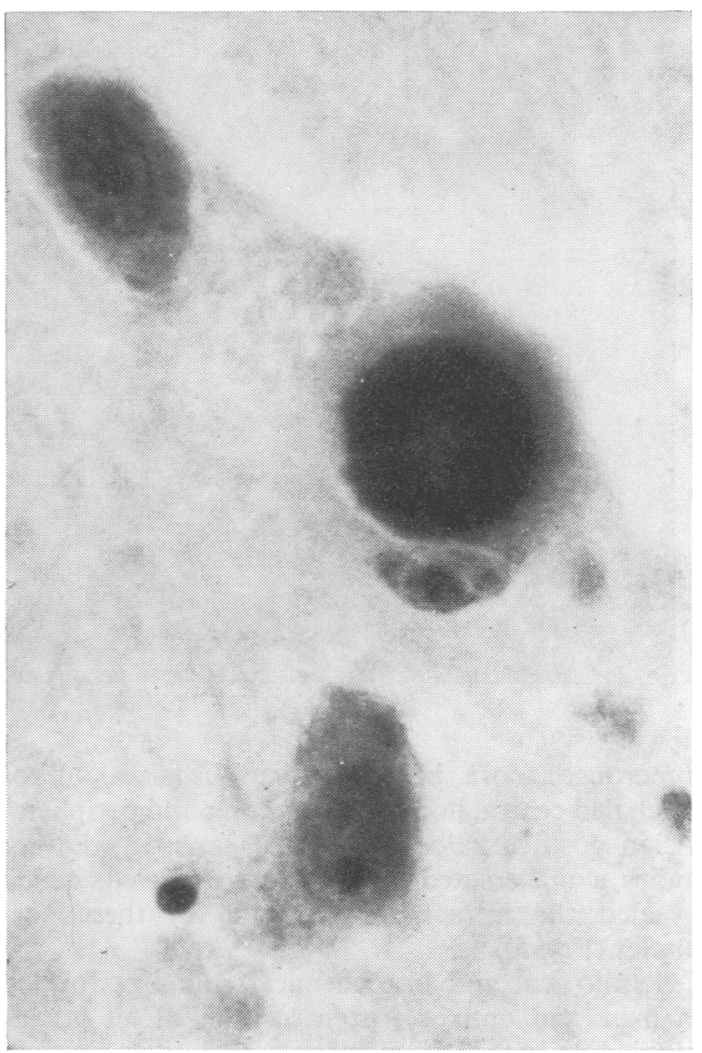

FIG. 5 Evidence of the intracellular position of $a$ Lafora body. $H$ and $E, \times 1500$.

POSTMORTEM EXAMINATION Necropsy was performed three hours after death. The 18 year old male weighed $43 \mathrm{~kg}$. There was severe emaciation and bilateral 'bronchopneumonia. The brain weighed $1.1 \mathrm{~kg}$ and macroscopic examination revealed uniformly atrophic hemispheres. The basal ganglia and thalami were normal in size. The external and cut surface of the cerebellum appeared normal. All other body organs were atrophic but otherwise normal on gross and microscopic examination.

Histological features Microscopically, some changes were found in the cerebral cortex, which showed a discrete neuronal depletion, but they were without architectural disturbances. Some corpora amylacea were found scattered in various regions, particularly below the basal ganglia.

In the granular layer (Fig. 2) and in some Purkinje cells of the cerebellar cortex (Fig. 3) were found 


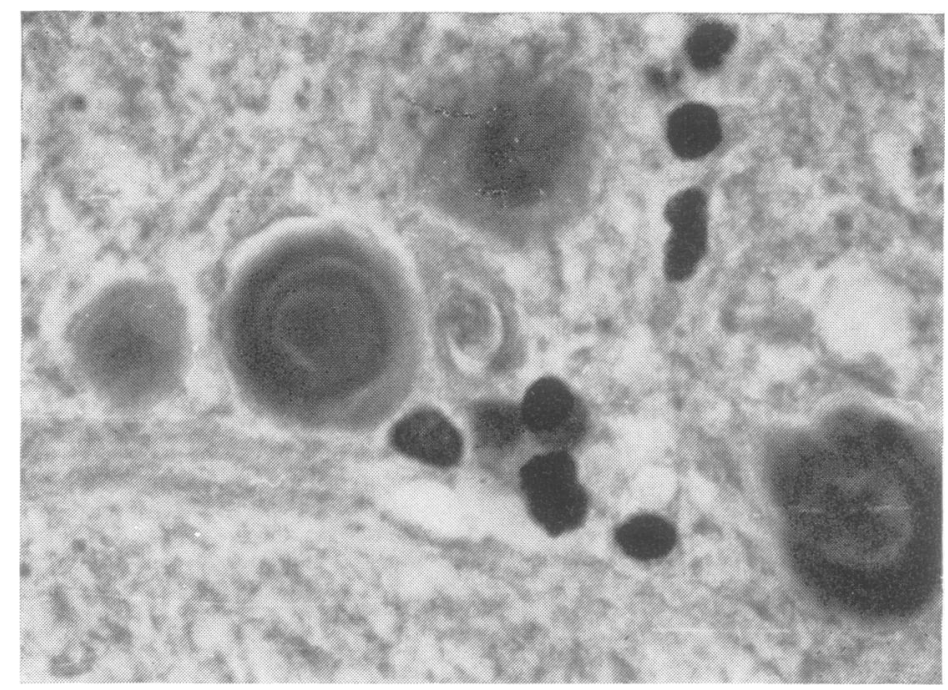

FIG. 6 Multilaminated corpora amylacea in cerebral white matter. $H$ and $E, \times 1100$.

numerous Lafora bodies of various sizes, all of which had central homogeneous cores and peripheral Alcian positive haloes (Fig. 4). Near many Lafora bodies a nucleolated nucleus was observed, which revealed the intracellular position of these corpuscles (Fig. 5).

Histological and histochemical stains performed on fixed and unfixed frozen sections of all organs revealed no pathological substances in the cells or in the interstitial tissues.

The presence of both corpora amylacea and Lafora bodies in the central nervous system caused us to make a histochemical study of the two inclusion types. Sections of the CNS were processed with traditional histological methods and with some histochemical reactions as suggested by Jaspar and Prick (1969). The methods were: for detection of proteins (Danielli's tetrazonium test), nucleic acids (Feulgen), lipids (Sudan black B, Sudan III and Nile blue), and carbohydrates (PAS, Alcian blue, AlcianPAS as described by Lillie (1965), toluidine blue, Congo red).

The results demonstrate a similar composition for the two types of corpuscles. In both types the central core was intensely PAS positive and the peripheral halo of the Lafora bodies or the concentric, multilaminated rim of the corpora amylacea (Fig. 6) were Alcian blue positive or feebly PAS positive. Reactions for proteins were feebly and inconsistently positive, and stains for lipids were negative.

\section{DISCUSSION}

Histopathological changes in the cerebellum such as cellular depletion of the granular layer and degenerative changes in the nuclei with or without the presence of Lafora bodies, have been described previously in some cases of progressive myoclonus epilepsy. In our case, Lafora bodies were present in the granular and Purkinje cell layers and the microscopical appearance of cerebellar structures was normal. Histochemical stains demonstrated a similar composition of the Lafora bodies and corpora amylacea which were both present in the CNS of this case, and only morphological studies have shown differences between multilaminated extracellular corpora amylacea and Lafora bodies with basophil central cores and homogeneous pale haloes. In the skeletal muscle of some cases of progressive myoclonus epilepsy, PAS positive or basophilic deposits have been found (Allegranza et al., 1963; Schwarz and Janoff, 1965; Van Heycop Ten Ham, 1965, 1974). Muscular atrophy in the extremities, described in most cases by Koskiniemi et al. (1974) was present, but no accumulation of pathological substance was found. A pathological classification of progressive myoclonus epilepsy by Franck and Reznik (1967) and Seitelberger (1968) distinguishes three groups of histopathological lesions (1) abiotrophic cases, (2) cases which belong to the group of familial amaurotic idiocy, and (3) cases where Lafora bodies are present in the cells of the brain. Because of the 
clinical pattern and of the numerous Lafora bodies in the cerebellum, this case could be classified in the Lafora group of progressive myoclonus epilepsy, even if no other lesions were found in the CNS or in other organs.

\section{REFERENCES}

Allegranza, A., Canevini, P., Garavaglia, G., and Marinato, G. (1963). Un caso di mioclono-epilessia: contributo anatomo-clinico. Il Lavoro Neuropsichiatrico, 34, 395-402.

Ammermann, O. (1940). Isolierte Schadigung der unteren Oliven bei Myoklonusepilepsie. Archiv für Psychiatrie und Nervenkrankheiten, 3, 213-232.

Anraku, S., Nakamura, K., and Omaru, I. (1965). Special type of myoclonus epilepsy. Proceedings of 8th International Congress of Neurology, Vienna, 4, 291-295.

Franck, G., and Reznik, M. (1967). L'épilepsie myoclonique progressive d'Unverricht-Lundborg. Etude anatomoclinique d'une forme abiotrophique. Acta Neurologica et Psychiatrica Belgica, 67, 713-730.

Jaspar, H. H., and Prick, J. (1969). Morphology and Histo- chemistry of the Corpora Amylacea in the Brain. 1 and 2 Proceedings. Series C.72 No. 4, 385-412. Konikle Akademie van Wetenschappen: Amsterdam.

Koskiniemi, M., Donner, M., and Haltai, M. (1974). Progressive myoclonus epilepsy. A clinical and histopathological study. Acta Neurologica Scandinavica, 50, 307-332.

Lillie, R. D. (1965). Histopathologic Technique and Practical Histochemistry, p. 510. McGraw-Hill: London.

Matthews, W. B., Howell, D. A., and Stevens, D. L. (1969). Progressive myoclonus epilepsy without Lafora bodies. Journal of Neurology, Neurosurgery, and Psychiatry, 32, 116-122.

Schwarz, G. A., and Janoff, M. (1965). Lafora's disease. Distinct clinico-pathological form of Unverricht's syndrome. Archives of Neurology, 12, 172-188.

Seitelberger, F. (1968). Myoclonus body disease. In Pathology of the Nervous System, vol. I, pp. 1121-1134. Edited by J. Minkler. McGraw-Hill: London.

Van Heycop Ten Ham, M. W. (1965). Lafora's disease (review and histochemical aspects). Archives of Neurobiology, 28, 647-666.

Van Heycop Ten Ham, M. W. (1974). Lafora's disease. A form of progressive myoclonus epilepsy. In Handbook of Clinical Neurology, vol. 15, pp. 382-422. American Elsevier: New York. 